\title{
Permanent magnet synchronous generator design solution for large direct- drive wind turbines: Thermal behavior of the LC DD-PMSG
}

\author{
Yulia Alexandrova, Robert Scott Semken, Juha Pyrhönen
}

\section{A B S T R A C T}

Wind is one of the most compelling forms of indirect solar energy. Available now, the conversion of wind power into electricity is and will continue to be an important element of energy self-sufficiency planning. This paper is one in a series intended to report on the development of a new type of generator for wind energy; a compact, high-power, direct-drive permanent magnet synchronous generator (DD-PMSG) that uses direct liquid cooling (LC) of the stator windings to manage Joule heating losses. The main param-eters of the subject LC DD-PMSG are $8 \mathrm{MW}, 3.3 \mathrm{kV}$, and $11 \mathrm{~Hz}$. The stator winding is cooled directly by deionized water, which flows through the continuous hollow conductor of each stator tooth-coil winding. The design of the machine is to a large degree subordinate to the use of these solid-copper tooth-coils. Both steady-state and timedependent temperature distributions for LC DD-PMSG were examined with calculations based on a lumpedparameter thermal model, which makes it possible to account for uneven heat loss distribution in the stator conductors and the conductor cooling system. Transient calculations reveal the copper winding temperature distribution for an example duty cycle during variable-speed wind turbine operation. The cooling performance of the liquid cooled tooth-coil design was predicted via finite element analysis. An instrumented cooling loop featuring a pair of LC tooth-coils embedded in a lamination stack was built and laboratory tested to verify the analytical model. Predicted and measured results were in agreement, confirming the predicted satisfactory operation of the LC DD-PMSG cooling technology approach as a whole.

\section{Introduction}

In recent years, intensive research efforts have focused on the development of high power electrical generators for wind turbine applications. Today, most land-based wind turbines have power ratings from $1.5 \mathrm{MW}$ to $3 \mathrm{MW}$, and wind turbines designed for offshore applications are typically 3 MW-5 MW. Sustaining the rapid growth in wind energy will require developing wind turbines with even higher power ratings, and there are several development projects under way targeting power ratings up to $15 \mathrm{MW}$ (e.g. Sway $10 \mathrm{MW}$ wind turbine [1], Azimut Project of $15 \mathrm{MW}$ wind turbine [2]).

Over the past decade, direct-drive (DD) electrical generators have become pervasive in wind turbines rated below $4 \mathrm{MW}$. They are now being used in higher power wind turbines. DD electrical generators enable direct coupling to the turbine blades, eliminating the gear box. The primary reason for the rapid acceptance of DD technology has been the energy savings associated with running an electrical generator at a lower speed, as well as the general reliability of such a drive system [3].

A review of electrical generators for DD wind turbines has been presented in Ref. [4]. As a result of progress in power electronics, 
software engineering, and materials; permanent magnet synchronous generators (PMSGs), made from modern rare earth magnet materials, are receiving increased attention for DD wind turbine applications.

The most unique feature of DD wind turbine electrical generators is their size. They operate below $30 \mathrm{rpm}$ (typically 10-15 rpm at $3 \mathrm{MW}$ ) and feature a relatively large diameter to length ratio. DD wind turbine electrical generators look like large diameter, slender rings. The large diameter allows high torque to be developed. Furthermore, substantial structural reinforcement is required to support the high torque developing in high power DD wind turbine electrical generators. Larger diameter and the need for adequate structural reinforcement leads to a truly massive structure. Therefore, one of the main problems facing the designers of large-power, large diameter DD wind turbine electrical generators is how to minimize its size and weight.

Size reduction of wind turbine electrical generators is ultimately limited by the ability to remove heat from the stator windings. The application of direct liquid cooling of the stator winding enables operation of the electrical generators at a higher output for a particular generator size as compared to an air cooled generator of the same size. Therefore, liquid cooled electrical generators may be smaller than forced air cooled electrical generators having the same rated power.

This paper is one in a series intended to report on the concept development of a new type of generator for wind energy; a compact, high-power DD-PMSG that uses direct liquid cooling (LC) of the stator windings to manage high Joule heating losses.

Cooling of the 8 MW LC DD-PPMSG is examined in more detail in this paper, and both steady-state and time-dependent temperature distributions were calculated and validated. There are typically three approaches used to predict the thermal performance of electrical machines: making calculations using simplified mathematical models, applying numerical method and taking experimental measurements. For instance, Farsane et al. [5] described an experimental cooling study for a closed electric motor. Based on measurements, modifications were suggested, and a new prototype casing was realized. Fenot et al. [6] studied, experimentally, flow and local heat transfer in the air gap of an open four-pole synchronous motor. Based on their heat transfer measurements, a correlation for heat transfer was derived corresponding to the rotor pole, rotor slot, and stator. However, for large electrical machines, it is cost prohibitive to build a full-scale prototype to make comprehensive thermal performance measurements.

Computational fluid dynamics (CFD) would be useful to understand heat transfer performance, and a number of CFD models of electrical machines have been developed. For instance, Srinivas et al. [7] used a CFD model to calculate the heat distribution in a switched reluctance motor with natural cooling. Jungreuthmayer et al. [8] modeled PMSM fluid flow and found good correspondence between temperatures predicted by the CFD analysis and values measured experimentally. Recently, CFD was used to evaluate the thermal performance of a $35 \mathrm{~kW}$ in-wheel motor operating in oilcooled mode [9]. Kolondzovski et al. [10] applied 3D computational analysis to investigate the temperature rise phenomena in a high-speed permanent magnet machine. However, CFD is computationally intensive, and therefore the approach is not feasible when repeated calculations are required or for large complex electrical machines.

Thermal analysis with lumped parameters could be applied as a preliminary approach to predicting the approximate thermal performance of large electrical machines. To date, research papers have been published describing lumped parameter thermal models of electrical machines equipped with indirectly cooled multi-turn coils [11-13]. An equivalent thermal circuit for a multi barrier interior PMSM was reported in Ref. [11] that assumed no circumferential heat flow and temperature variance only in the radial direction. Nerg et al. [12] described a lumped parameter thermal model for radial-flux electrical machines of high power density under steady state thermal conditions. That model has been applied to a high-speed induction motor, and a low-speed PMSM and PMSG in considerably different size categories. In Ref. [13], the authors have proposed a lumped parameter thermal model for axial flux permanent magnet machines. The model was validated by comparing results to experimental data. In Ref. [14], the thermal network method based on two-dimensional heat conduction in hollow cylinder geometry was applied to build the thermal model of an electric motor and to calculate its maximum temperature rise. An analytical layered thermal model to calculate the temperature distribution in the winding of an oil-filled transformer with zigzag cooling ducts is described in Ref. [15]. However, there have been few papers published that describe the application of lumped parameter models to analyze the forced cooling of stator windings composed of form wound copper conductors.

The authors of Ref. [16] presented a lumped parameter model of an LC DD-PMSG using the equivalent thermal conductivity of the stator windings. Here, we extend their lumped parameter thermal model to include the detailed thermal model of the stator slot and to include the previously excluded coolant flow arrangement. As a result, the new model more accurately estimates temperatures by accounting for the non-uniform distribution of copper losses resulting from the skin effect. The proposed lumped-parameter thermal model is suitable for integration with the algorithm presented in Ref. [17] to optimize LC DD-PMSG design.

\section{Design and cooling concept of the LC DD-PMSG}

The large air gap diameter of a high-power wind turbine generator, e.g. $5 \mathrm{~m}$ or more, requires segmented construction. The rotor and stator magnetic circuits are divided into some number of identical units. These units are connected electrically in series or in parallel to get desired voltage levels. There are many variations for the number of units in this basic design, including $6,8,10,12$ units, and so on. This paper focuses on an 8 MW outer rotor LC DD-PMSG constructed of 12 identical stator and rotor segments. Stator air-gap diameter and active stator length are $6.93 \mathrm{~m}$ and $1.15 \mathrm{~m}$ respectively. Each of the stator segments has 12 slots. The total number of slots for the 12 stator segments of the generator is, therefore, 144. The rotor comprises 10 magnet poles per segment for a total of 120 permanent magnet poles ( 60 pole pairs). This configuration results in a rated frequency of $10-12 \mathrm{~Hz}$, which is still acceptable for the cyclic loading of the converter's insulated-gate bipolar transistors. The combination of 60 pole pairs and 144 stator slots results in a fractional slot concentrated non-overlapping winding (or tooth-coil winding) in which each winding phase coil is concentrated around individual teeth and thus does not span adjacent teeth or coils, simplifying direct liquid cooling. Such a machine works at the fifth harmonic of the stator current linkage using it as the means of electromechanical power conversion. The fundamental harmonic is of minimal significance [18]. Fig. 1 shows a detailed view of the LC DD-PMSG. This LC DD-PMSG has liquid-cooled windings in the stator and rotor-surface-mounted permanent magnets. Both the stator and rotor are based on a laminated steel structure.

A tooth-coil winding architecture offers the most straightforward approach to direct liquid cooling of the stator conductors. Each tooth-coil is an elongated continuous two-layer winding of copper that is shaped to fit into the slots on either side of a laminated stator tooth. See a photo in Fig. 2. The cross section of the wound conductor is rectangular. Since it forms a closed loop, the tooth-coil itself can be used as a coolant transport conduit. Stainless 


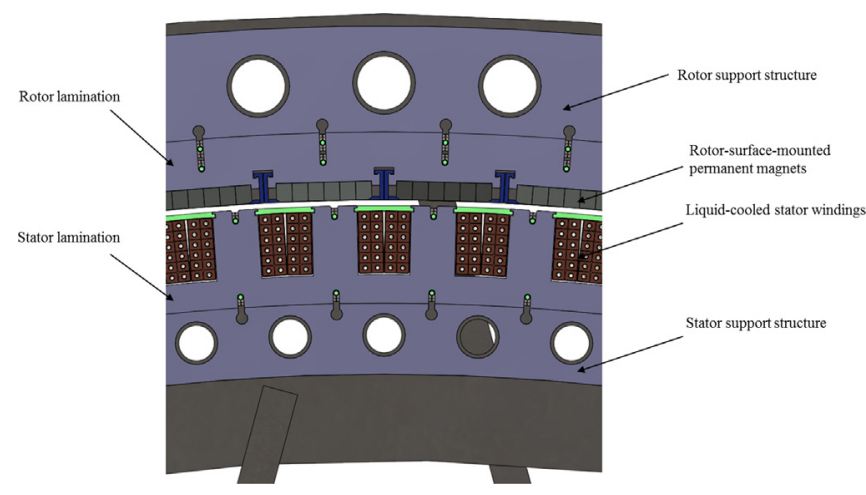

Fig. 1. Concept design of the active regions and supporting structures of the LC DD-PMSG.

steel tubing embedded within the copper at its centerline serves as the coolant channel. The stainless steel (316 series) offers high electrical resistivity, good mechanical strength, and corrosion and erosion resistance. Tooth-coil coolant enters the inner winding layer from the bottom, draws heat out of the copper, and leaves the coil again from the bottom of the outer layer.

The copper is wrapped with a thin layer of insulation to electrically isolate adjacent conductors. The two winding layers for each tooth-coil form two conductor columns on either side of the tooth. Between each conductor column and between the tooth-coil and the stator laminations are another more substantial layer of insulation.

Each tooth-coil is connected to the cooling loop via the stainless steel tubing through an electrically isolating coolant manifold. The manifold can be made of Ultem polyetherimide (PEI). Electrical connections are made using terminal lugs (shown in the photo of Fig. 2). Table 1 gives relevant characteristics for an 8 MW LC DD-PMSG tooth-coil.

\section{Layered lumped-parameter thermal model}

An accurate evaluation of temperature distribution is necessary to design a liquid cooled generator with an acceptable thermal performance margin. Lumped parameter thermal model was used to carry out the required thermal analysis. The lumped parameter thermal model neglects axial temperature variation. The heat transfer paths between the different generator parts are represented using thermal resistances at constant temperature. The heat flow paths defined for the equivalent steady-state lumped parameter thermal model of the LC DD-PMSG are shown in Fig. 3.

A portion of the heat localized within each stator tooth flows through the slot and tooth-coil insulation material, through the

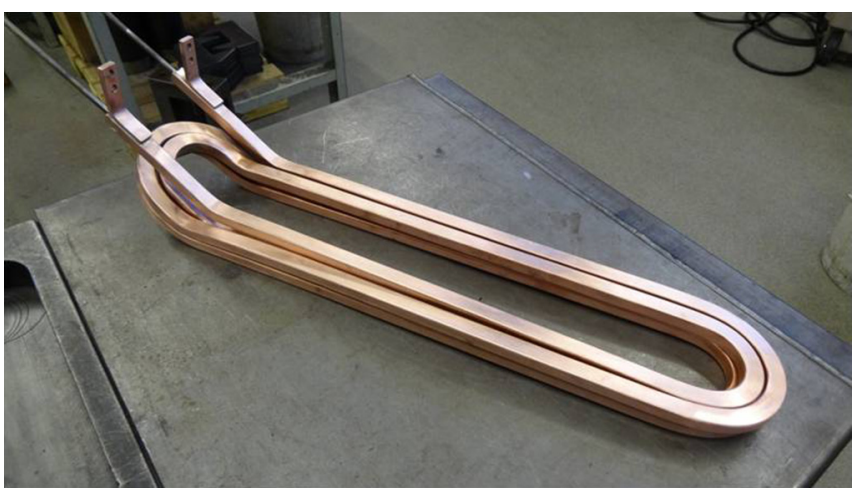

Fig. 2. Liquid-cooled tooth-coil shown without insulation.
Table 1

Tooth-coil characteristics.

\begin{tabular}{ll} 
Number of turns in tooth-coil & 10 \\
Conductor length & $1.4 \mathrm{~m}$ \\
Conductor size (width $\times$ height) & $18 \mathrm{~mm} \times 15 \mathrm{~mm}$ \\
Cooling hole diameter & $5.5 \mathrm{~mm}$ \\
Weight per tooth coil & $58 \mathrm{~kg}$ \\
Number of cooling circuit per tooth-coil & 1 \\
\hline
\end{tabular}

copper, and into the coolant. Heat also flows along the stator teeth to the air gap and along the stator tooth to the yoke. Some of the heat generated in the permanent magnets of the rotor can flow into the rotor, and some can flow into the stator through the air gap.

The stator laminations are bound tightly together with a number of tensioned rods passing through them. This construction increases the total surface area of the laminations exposed to the convecting cooling air, which enhances heat removal since the additional heat transfer is proportional to the increase in surface area.

Temperature distribution analysis began by assigning the following losses or heat source values for an 8 MW LC DD-PMSG. The losses are subdivided into the contributions by the various parts, i.e., the stator yoke and teeth, the rotor yoke, the permanent magnets, stator winding, and the air gap. Table 2 reports the loss division at the rated load.

Because of the negligible stator iron losses in a low-speed, low-frequency generator; the steady-state temperature rise in the stator winding depends mainly on the copper losses. The complex heterogeneous structure of indirectly air-cooled stator windings is usually replaced with a single homogeneous material that reproduces a representative thermal behavior. Equivalent thermal conductivity is used [19]. However, to improve temperature prediction accuracy, a detailed thermal model of the stator slot is developed, in which all the adjacent conductors in the cooling circuit are modeled separately with a corresponding equivalent convective thermal circuit. The convection thermal circuit is executed so that, for each cooling circuit, the outlet coolant temperature of each preceding conductor becomes the inlet coolant temperature of the subsequent conductor. Heat transfer from the end windings is not modeled separately. End windings were taken into account by increasing coolant channel length by factor $k_{\text {ew }}$.

\section{Analysis of heat transfer performance}

\subsection{Limiting temperature}

The minimum inlet coolant temperature of a liquid cooled winding is limited by the strength of the conductor insulation material. If the cooling liquid is too cold, thermal shock may lead to insulation failure. On the other hand, if the inlet coolant temperature is too high, heat will not be effectively removed, and there is an even greater danger of insulation failure. According to Ref. [20], the recommended water temperature range at the inlet of a direct liquid cooling circuit is from $33^{\circ} \mathrm{C}$ to $50^{\circ} \mathrm{C}$. According to Ref. [21], the temperatures range from $45^{\circ} \mathrm{C}$ to $50{ }^{\circ} \mathrm{C}$. Coolant temperature at the coil outlet is usually maintained below $80^{\circ} \mathrm{C}$ to provide a sufficient margin to ensure that stator conductor temperatures do not exceed safe levels even during abnormal operating conditions. According to the international standard for rotating electrical machines (IEC 60034-1 [22]) coolant outlet temperatures must not exceed $90{ }^{\circ} \mathrm{C}$ in any event. Coolant temperature rise, the difference between outlet and inlet temperatures, must be kept below $30^{\circ} \mathrm{C}$ at rated power assuming an average ambient temperature of $35^{\circ} \mathrm{C}$. 


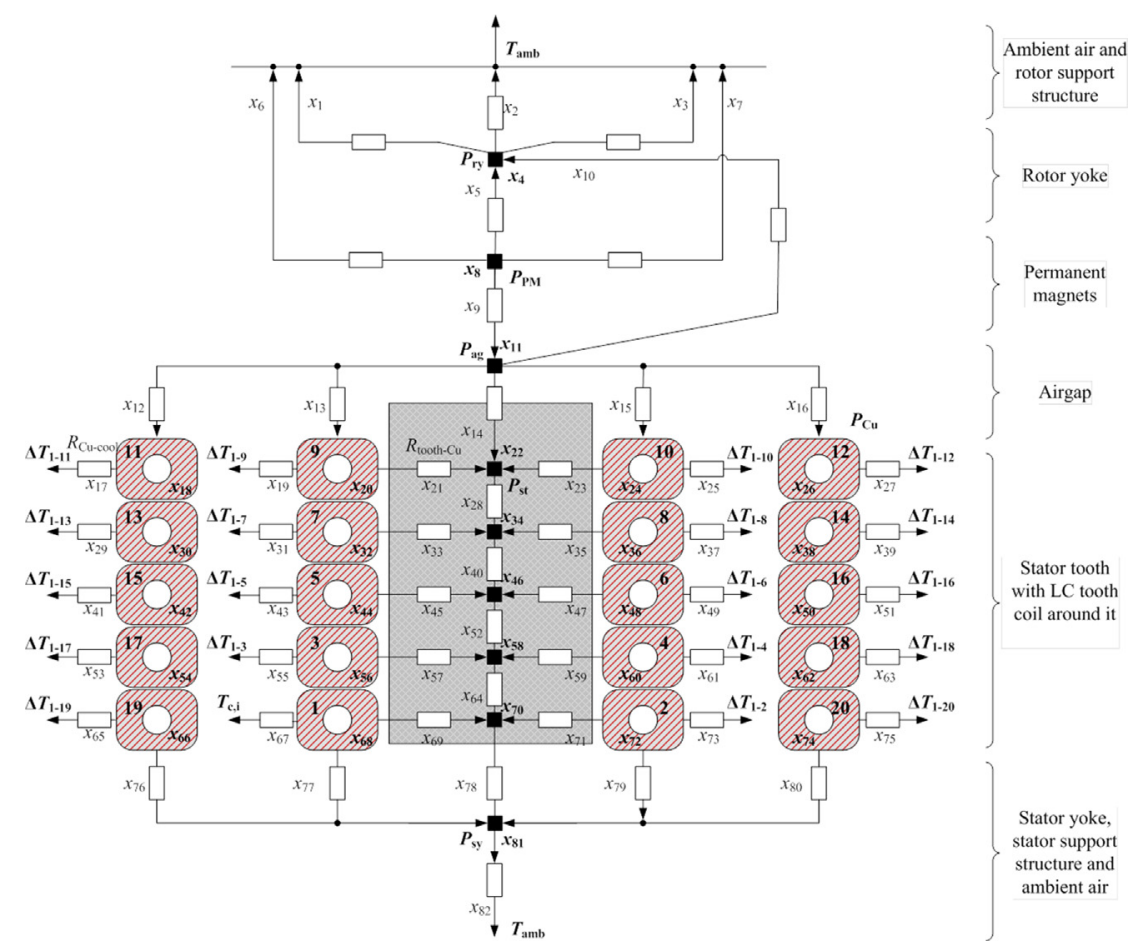

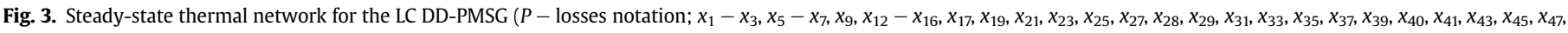
$x_{49}, x_{51}, x_{52}, x_{53}, x_{55}, x_{57}, x_{59}, x_{61}, x_{63}, x_{64}, x_{65}, x_{67}, x_{69}, x_{71}, x_{73}, x_{75}, x_{76}-x_{80}, x_{82}$ - heat flows notation; $x_{4}, x_{8}, x_{11}, x_{18}, x_{20}, x_{22}, x_{24}, x_{26}, x_{30}, x_{32}, x_{34}, x_{36}, x_{38}, x_{42}, x_{44}$,

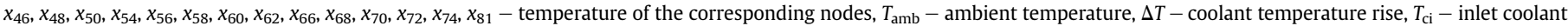
temperature).

\subsection{Steady state thermal loads}

Copper temperature is a function of coolant temperature, so the temperature of the coolant must be known to predict copper temperature. Two equations describing heat transfer in single phase steady state flow are used to evaluate outlet coolant temperature. Equation (1) relates to the physical change in the coolant brought about by the heat transfer system. Equation (2), an expression of Newton's law of cooling, is system related and considers cooling system specifics such as flow and heat transfer surface area.

$P_{\mathrm{Cu}-\mathrm{c}, j} k_{\mathrm{R}, j}=c_{\mathrm{p}, \mathrm{c}} \rho_{\mathrm{c}} S_{\mathrm{cch}} v_{\mathrm{c}}\left(T_{\mathrm{co}, j}-\frac{\sum_{i=1}^{j-1} P_{\mathrm{Cu}-\mathrm{c}, i} k_{\mathrm{R}, i}}{c_{\mathrm{c}} \rho_{\mathrm{c}} S_{\mathrm{cch}} v_{\mathrm{c}}}\right)$,

$P_{\mathrm{Cu}-\mathrm{c}, j} k_{\mathrm{R}, j}=\Pi_{\mathrm{cch}} l_{\mathrm{s}} k_{\mathrm{ew}} \alpha_{\mathrm{c}}\left(T_{\mathrm{Cu}, j}-\frac{\frac{\sum_{i=1}^{j-1} P_{\mathrm{cu}-\mathrm{c},} k_{\mathrm{R}, i}}{\mathcal{c}_{\mathrm{c}} \rho_{\mathrm{c}} S_{\mathrm{cch}} v_{\mathrm{c}}}+T_{\mathrm{co}, j}}{2}\right)$,

where $c_{\mathrm{p}, \mathrm{c}}$ is coolant heat capacity, $j$ is the index of the conductor belonging to the coolant circuit, $k_{\mathrm{R}}$ is the factor for electrical resistivity increase as temperature increases, $l_{\mathrm{S}}$ is stator length, $P_{\mathrm{Cu}-\mathrm{c}}$ is heat removed by the coolant, $S_{\mathrm{cch}}$ is the cooling channel crosssectional area, $T_{\mathrm{co}}$ is coolant outlet temperature, $T_{\mathrm{Cu}}$ is conductor average temperature, $\alpha_{\mathrm{c}}$ is heat transfer coefficient, $\Pi_{\mathrm{cch}}$ is cooling channel hydraulic perimeter, $\rho_{\mathrm{c}}$ is coolant density, and $v_{\mathrm{c}}$ is coolant velocity.
The heat transfer coefficients for convection rely on the proven empirical convection correlations models available in heat transfer literature [23].

In Equations (1) and (2), the inlet coolant temperature of the $j$ th conductor depends on the total heat removed by the coolant having flowed through adjacent $(j-1)$ conductors of the cooling circuit. These equations interact in a related way, and the heat transfer balance equations can be written as:

$T_{\mathrm{Cu}, j}-\frac{P_{\mathrm{Cu}-\mathrm{c}, j} k_{\mathrm{R}, j}}{\Pi_{\mathrm{cch}} k_{\mathrm{ew}} l_{\mathrm{s}} \alpha_{\mathrm{c}}}=\frac{1}{2} \frac{P_{\mathrm{Cu}-\mathrm{c}, j} k_{\mathrm{R}, j}}{c_{\mathrm{p}, \mathrm{c}} \rho_{\mathrm{c}} S_{\mathrm{cch}} v_{\mathrm{c}}}+\frac{\sum_{i=1}^{j-1} P_{\mathrm{Cu}-\mathrm{c}, i} k_{\mathrm{R}, i}}{c_{\mathrm{p}, \mathrm{c}} \rho_{\mathrm{c}} S_{\mathrm{cch}} v_{\mathrm{c}}}$,

where the heat $P_{\mathrm{Cu}-\mathrm{c}, j}$ is evaluated from the thermal circuit iteratively.

\subsection{Transient thermal loads}

Short term generator current overloading may increase the temperature of the stator winding to dangerous levels. Theoretical temperature transient calculations have been made by Kazovskij [20]. Temperature does not respond immediately to changes in

Table 2

Electromagnetic and mechanical losses of the studied 8 MW LC DD-PMSG.

\begin{tabular}{lc}
\hline Power loss component & Value $(\mathrm{kW})$ \\
\hline Stator copper winding loss, $P_{\mathrm{Cu}}$ & 550 \\
Stator tooth iron loss, $P_{\mathrm{st}}$ & 5 \\
Stator yoke iron loss, $P_{\text {sy }}$ & 3.7 \\
Eddy current losses in permanent magnets, $P_{\mathrm{PM}}$ & 30 \\
Rotor yoke iron, $P_{\mathrm{ry}}$ & 1 \\
Air gap friction loss, $P_{\mathrm{ag}}$ & 1.5 \\
\hline
\end{tabular}


generator load. Its time variation follows an exponential law, where the steepness of the curve decreases with time. The transient temperature solution for the copper conductor can be written as follows.

$$
\begin{aligned}
& T_{\mathrm{Cu}}(t)=T_{\mathrm{Cu}, k_{\mathrm{j}}=1}\left(1-e^{-t / \tau_{0}}\right)+T_{\mathrm{Cu}, k_{\mathrm{j}} \neq 1} e^{-t / \tau_{0}}, \\
& T_{\mathrm{Cu}, k_{\mathrm{j}}=1}=\frac{P_{\mathrm{Cu}-\mathrm{c}} k_{\mathrm{R}}}{l_{\mathrm{s}} k_{\mathrm{ew}}}\left(\frac{x}{\rho_{\mathrm{c}} c_{\mathrm{p}, \mathrm{c}} S_{\mathrm{cch}} v_{\mathrm{c}}}+\frac{1}{\alpha_{\mathrm{c}} \Pi_{\mathrm{cch}}}\right), \\
& T_{\mathrm{Cu}, k_{\mathrm{j}} \neq 1}=T_{\mathrm{Cu}, k_{\mathrm{j}}=1} k_{\mathrm{j}}^{2} k_{\mathrm{R}},
\end{aligned}
$$

where $k_{\mathrm{j}}$ is the current density increase factor, $T_{\mathrm{Cu}}$ is the conductor steady-state temperature, $x$ is the distance measured along the cooling channel from the coolant inlet position, and $\tau_{0}$ is the thermal time constant.

Because of the consistent thermal barrier created by slot insulation as well as the low heating velocity of the stator core, copper heating is independent of stator core heating at the beginning of transients. The difference between the copper losses dissipated before and after overloading will heat the winding. The thermal time constant $\tau_{0}$ depends on the copper and coolant properties.

$$
\begin{aligned}
\tau_{0} \cong \frac{\rho_{\mathrm{Cu}} c_{\mathrm{p}, \mathrm{Cu}} S_{\mathrm{Cu}}}{\alpha \Pi_{\mathrm{cch}}} 1 & +\frac{\rho_{\mathrm{c}} c_{\mathrm{p}, \mathrm{c}} S_{\mathrm{cch}}}{\rho_{\mathrm{Cu}} c_{\mathrm{p}, \mathrm{Cu}} S_{\mathrm{Cu}}} \\
& \left.+\frac{\left(\rho_{\mathrm{c}} c_{\mathrm{p}, \mathrm{c}} S_{\mathrm{cch}}+\rho_{\mathrm{Cu}} c_{\mathrm{p}, \mathrm{Cu}} S_{\mathrm{Cu}}\right) \alpha \Pi_{\mathrm{cch}} l_{\mathrm{cch}}}{\rho_{\mathrm{Cu}} \rho_{\mathrm{c}} c_{\mathrm{p}, \mathrm{Cu}} c_{\mathrm{p}, \mathrm{c}} S_{\mathrm{Cu}} S_{\mathrm{cch}} v_{\mathrm{c}}}\right),
\end{aligned}
$$

where $c_{\mathrm{p}, \mathrm{Cu}}$ is copper heat capacity, $l_{\mathrm{cch}}$ is the total length of the cooling circuit, $S_{\mathrm{Cu}}$ is the copper cross-section area, $\rho_{\mathrm{C}}$ is copper density.

Existing requirements [24] for hydro generator design with directly cooled stator windings dictate the need for continuous operation over a definite period of time during operations with increased stator current density. Hydro generator manufacturers provide guidance on how long liquid-cooled generators can continue to operate with rated cooling conditions in the event of increased stator current (Table 3).

\subsection{Fault of coolant supply to the stator winding}

A failure of the pump or a break in the coolant lines can result in a loss of coolant to the stator winding. In the absence of coolant circulation, stator winding temperatures increase considerably. According to [24], a hydro power generator with directly cooled stator winding should be capable of operating without injury for $60 \mathrm{sec}$ at $50 \%$ of its rated current following a loss of coolant event. The same criterion is applied here. Copper and coolant temperature

Table 3

Permissible operation durations for over currents based on rated coolant flow properties.

\begin{tabular}{ll}
\hline Operation duration & Stator current $(\%)$ \\
\hline Continuous & 110 \\
$15 \mathrm{~min}$ & 115 \\
$6 \mathrm{~min}$ & 120 \\
$5 \mathrm{~min}$ & 125 \\
$4 \mathrm{~min}$ & 130 \\
$3 \mathrm{~min}$ & 135 \\
$2 \mathrm{~min}$ & 140 \\
$1 \mathrm{~min}$ & 150 \\
$20 \mathrm{sec}$ & 200 \\
\hline
\end{tabular}

distributions with respect to time are described by the following equations [25].

$$
\begin{aligned}
T_{\mathrm{Cu}}(t)= & \left.\left.\frac{c_{2}}{1+c_{1}} t+\frac{c_{1}^{2}}{1+c_{1}} \tau_{0}^{\prime} 1-e^{-\frac{t 1+c_{1}}{\tau_{0}^{\prime} c_{1}}}\right)\right) \\
& \left.+\frac{P_{\mathrm{Cu}-\mathrm{c}} k_{\mathrm{R}}}{\alpha \prod_{\mathrm{cch}} l_{\mathrm{cch}}} \frac{1}{1+c_{1}} 1+c_{1} e^{-\frac{t^{1}+c_{1}}{\tau_{0}^{\prime} c_{1}}}\right)+\frac{P_{\mathrm{Cu}-\mathrm{c}} k_{\mathrm{R}}}{c_{\mathrm{p}, \mathrm{c}} \gamma_{\mathrm{c}} S_{\mathrm{cch}} v_{\mathrm{c}}},
\end{aligned}
$$

$$
\begin{aligned}
T_{\mathrm{c}}(t)= & \left.\left.\frac{c_{2}}{1+c_{1}} t-\frac{c_{1}}{1+c_{1}} \tau_{0}^{\prime} 1-e^{-\frac{t}{\tau_{0}^{\prime}} \frac{1+c_{1}}{c_{1}}}\right)\right) \\
& \left.+\frac{P_{\mathrm{Cu}-\mathrm{c}} k_{\mathrm{R}}}{\alpha \Pi_{\mathrm{cch}} l_{\mathrm{cch}}} \frac{1}{1+c_{1}} 1-e^{-\frac{t}{\tau_{0}^{\prime}} \frac{1+c_{1}}{c_{1}}}\right)+\frac{P_{\mathrm{Cu}-\mathrm{c}} k_{\mathrm{R}}}{c_{\mathrm{p}, \mathrm{c}} \gamma_{\mathrm{c}} S_{\mathrm{cch}} v_{\mathrm{c}}}
\end{aligned}
$$

$c_{1}=\frac{c_{\mathrm{p}, \mathrm{c}} m_{\mathrm{c}}}{c_{\mathrm{p}, \mathrm{Cu}} m_{\mathrm{Cu}}}, \quad c_{2}=\frac{P_{\mathrm{Cu}-\mathrm{c}} k_{\mathrm{R}}}{c_{\mathrm{p}, \mathrm{Cu}} m_{\mathrm{Cu}}}, \quad \tau_{0}^{\prime}=\frac{c_{\mathrm{p}, \mathrm{Cu}} m_{\mathrm{Cu}}}{\alpha \prod_{\mathrm{cch}} l_{\mathrm{cch}}}$,

where $m_{\mathrm{c}}$ is the coolant mass, and $m_{\mathrm{Cu}}$ is the copper mass.

\section{Validation of the model and results}

The developed analytical models have been applied to a design of an 8 MW LC DD-PMSG to predict thermal performance. Water was selected as the coolant. The conductor dimensions were adjusted to the values shown in Table 1 . According to Table 4, the generator achieves its rated power at approximately $81^{\circ} \mathrm{C}$ coolant average temperature at the outlet of the tooth-coil. With a flow velocity of $1 \mathrm{~m} / \mathrm{sec}$ a round tube removes on average $0.9 \mathrm{~W} / \mathrm{cm}^{2}$ with a mean tooth-coil temperature rise of approximately $40^{\circ} \mathrm{C}$.

With the form-wound structure of the studied LC tooth-coil stator winding, hot spots are always in a predictable location at the slot portion of the stator laminations. As a result, hot spot temperature can be calculated and duplicated from one stator slot to another. Therefore, steady-state thermal 2D FEA (Flux 2D, Cedrat) was carried out for a one slot pitch model to assess LC DDPMSG thermal performance at its rated load steady-state condition.

The 2D approach was chosen based on an assumption of planar heat flow. This assumption is relevant for active liquid cooling, because heat flow is almost purely radial due to the effective liquid cooling mechanism. The slot pitch model consisted of 20 liquidcooled hollow copper conductors with associated heat fluxes in terms of copper loss, slot insulation, wedge, stator yoke, and stator tooth with associated heat flux in term of stator iron loss. Air convection was applied to the inner and outer stator surfaces. The defined convection coefficient of $8500 \mathrm{~W} /\left(\mathrm{m}^{2} \mathrm{~K}\right)$ for inside the copper hollow conductors was approximately equal to a water velocity of $1 \mathrm{~m} / \mathrm{s}$. Fig. 4 shows the temperature distribution results, which agree well with the results from the analytical thermal model (see Table 4).

The results of the transient analysis, presented in Fig. 5, were computed using the procedure described in Sections 4.3 and 4.4. The transient model enables prediction of the time evolution of stator winding temperature. The calculated thermal time constant was $236 \mathrm{sec}$. The maximum temperatures of each conductor with respect to time can be determined from Fig. 5. The initial total copper loss was $550 \mathrm{~kW}$. The effect of increasing temperature on the electrical resistivity of copper conductors, and therefore the copper losses, was accounted by the $k_{\mathrm{R}}$ factor. For the first case, the current density increase factor $k_{\mathrm{j}}$ was set to 1.1 . The coolant velocity was $1 \mathrm{~m} / \mathrm{s}$. The results show the generator can operate continuously without reaching the temperature limit. For the second case, the 
Table 4

Calculated steady-state temperatures at rated load at different parts of 8 MW LC DD-PMSG.

\begin{tabular}{|c|c|c|c|}
\hline $\begin{array}{l}\text { Conductor number in the coolant path } \\
\text { (initial copper losses) }\end{array}$ & $\begin{array}{l}\text { Copper (liquid) } \\
\text { temperature, }{ }^{\circ} \mathrm{C}\end{array}$ & $\begin{array}{l}\text { Conductor number in the coolant path } \\
\text { (initial copper losses) }\end{array}$ & $\begin{array}{l}\text { Copper (liquid) } \\
\text { temperature, }{ }^{\circ} \mathrm{C}\end{array}$ \\
\hline Cond. 1 (150 W) & $42.6(42.0)$ & Cond. 11 (250 W) & $63.7(63.1)$ \\
\hline Cond. $2(150 \mathrm{~W})$ & $44.5(43.9)$ & Cond. 12 (250 W) & $66.3(65.7)$ \\
\hline Cond. $3(160 \mathrm{~W})$ & $46.3(45.8)$ & Cond. $13(215 \mathrm{~W})$ & $66.3(65.7)$ \\
\hline Cond. $4(160 \mathrm{~W})$ & $48.1(47.6)$ & Cond. 14 (182 W) & $68.4(68.0)$ \\
\hline Cond. 5 (184 W) & $50.1(49.6)$ & Cond. 15 (182 W) & $70.7(70.3)$ \\
\hline Cond. $6(184 \mathrm{~W})$ & $51.9(51.4)$ & Cond. $16(160 \mathrm{~W})$ & $72.6(72.2)$ \\
\hline Cond. 7 (222 W) & $54.1(53.5)$ & Cond. 17 (160 W) & $73.2(72.9)$ \\
\hline Cond. 8 (222 W) & $56.1(55.6)$ & Cond. $18(160 \mathrm{~W})$ & $74.5(74.1)$ \\
\hline Cond. 9 (283 W) & $58.7(58.1)$ & Cond. 19 (147 W) & $79.5(79.2)$ \\
\hline Cond. 10 (283 W) & $61.1(60.5)$ & Cond. 20 (147 W) & $81.1(80.8)$ \\
\hline Stator tooth, ${ }^{\circ} \mathrm{C}$ & 52.7 & & \\
\hline Stator yoke, ${ }^{\circ} \mathrm{C}$ & 51.5 & & \\
\hline Permanent magnet, ${ }^{\circ} \mathrm{C}$ & 67.7 & & \\
\hline Air gap, ${ }^{\circ} \mathrm{C}$ & 67.3 & & \\
\hline Rotor yoke, ${ }^{\circ} \mathrm{C}$ & 57.0 & & \\
\hline
\end{tabular}

current density was increased by a factor of 2 . Within $20 \mathrm{sec}$, the copper conductor heats up from the rated operational temperature to the temperature limit of $90^{\circ} \mathrm{C}$.

Installed in a variable-speed wind turbine, the LC DD-PMSG is supposed to be operated according to its torque curve (Fig. 6).

Generator speed varies between 3 and $11 \mathrm{rpm}$. Once the wind turbine rotor reaches the rated $11 \mathrm{rpm}$ speed, generator torque is increased until the generator is producing its maximum rated power.

Fig. 6 illustrates that generator output power, which depends on wind speed, varies significantly. The actual duty cycle of an LC DDPMSG during operation is complex. However, it can be approximated with a train of square pulses of power with different amplitudes and time durations (see Fig. 7). The copper temperature response to the duty-cycle was obtained according to Equation (4) in a discretized form (see Fig. 7). The initial temperature at the power square wave is taken from the final time moment of the previous square wave.

The 8 MW LC DD-PMSG can operate at even higher loads and remain within safe thermal operating limits without modifying the cooling system. The rated point of this machine type is defined by its economic optimum rather than thermal limits as in traditional machines. Naturally, efficiency falls as the machine becomes overloaded.
Fig. 8 shows that copper and coolant temperatures increase at approximately $0.05{ }^{\circ} \mathrm{C}$ per s when there is no coolant flow and 50\% of generator rated current is applied.

Therefore, the studied LC DD-PMSG can operate without coolant circulation for about $60 \mathrm{~s}$ at $50 \%$ of its rated current.

\section{LC tooth-coils prototype}

To validate the simulation results and to demonstrate the liquidcooling technology with its applications in a stator implementation, a small prototype with two liquid-cooled tooth-coils was designed, built, and tested at the Lappeenranta University of Technology. The specific goals for the prototype were to prove the feasibility of manufacturing the LC DD-PMSG tooth-coils and demonstrate the effectiveness of direct liquid cooling of the stator copper conductors. The instrumented loop provided thermal performance data to clarify the dependence and distribution of temperatures within the coils as well as to make comparison between theoretical and practical results.

Fig. 9 is a photo of the instrumented small prototype. It was located in a room free of forced air movement and oriented so the slot conductors were horizontal. The apparatus comprises the coils (1), the inlet and outlet coolant manifold (2), connection to the power source (3), a coolant reservoir (4), the pump (5), the heat

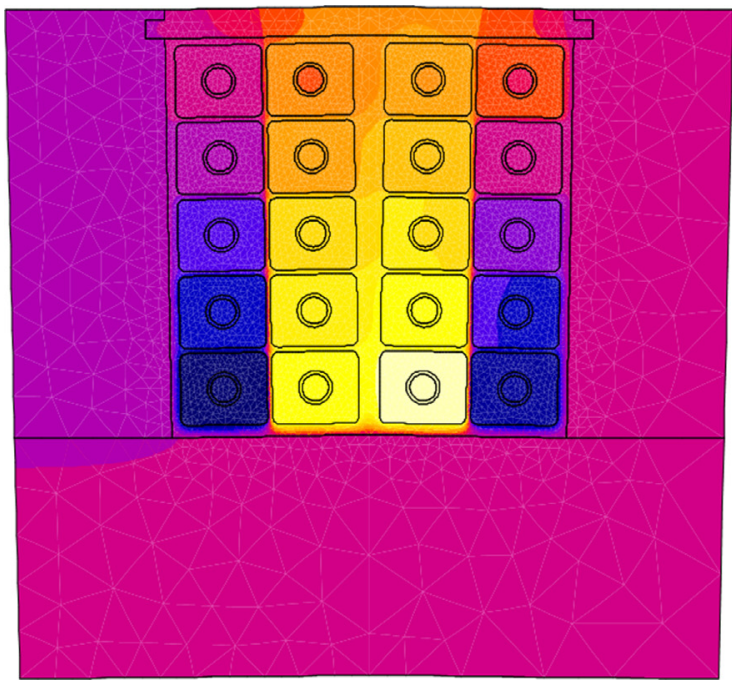

Temperature degrees $\mathrm{C}$

Fig. 4. Steady-state temperature predicted by 2D FEA model. 


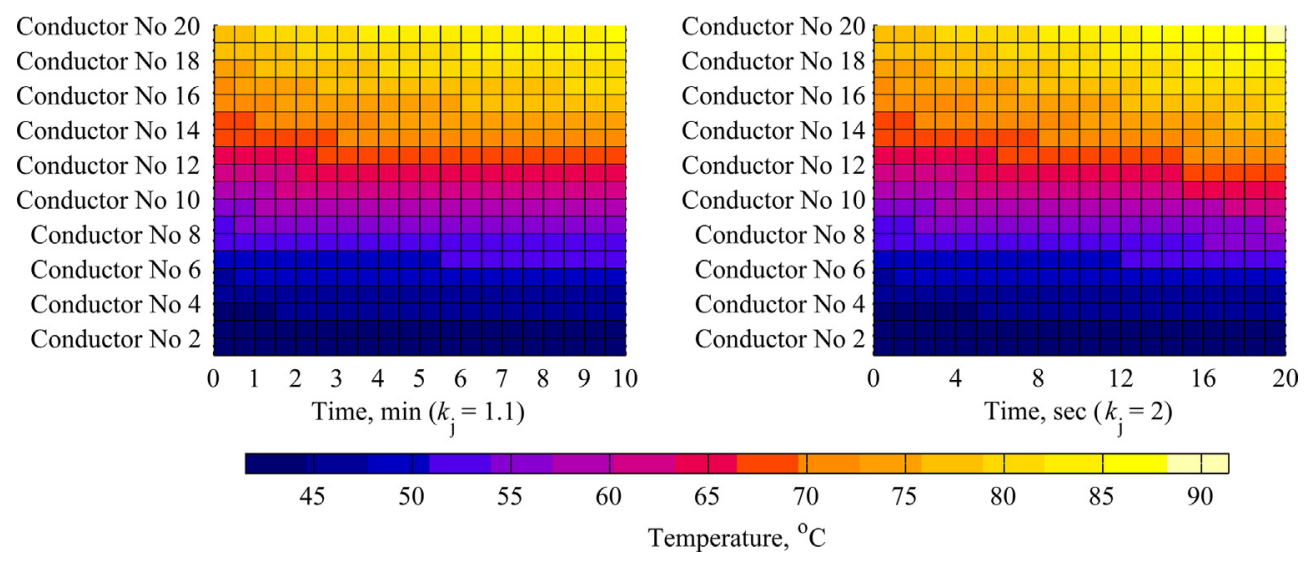

Fig. 5. Conductor temperature distribution with coolant velocity $1 \mathrm{~m} / \mathrm{s}$ for current density increase factor $k_{\mathrm{j}}=1.1$ and $k_{\mathrm{j}}=2$.

exchanger (6), coolant filters (7), a volumetric flow transducer (8), conductor temperature measurement RTDs (9), coolant pressure transducers and thermocouples (10), the power control system (11), and the data acquisition and processing system (12). All the instruments were calibrated prior to testing. The coolant was ECOCUT HS, a polyalphaolefin (PAO) heat transfer fluid.

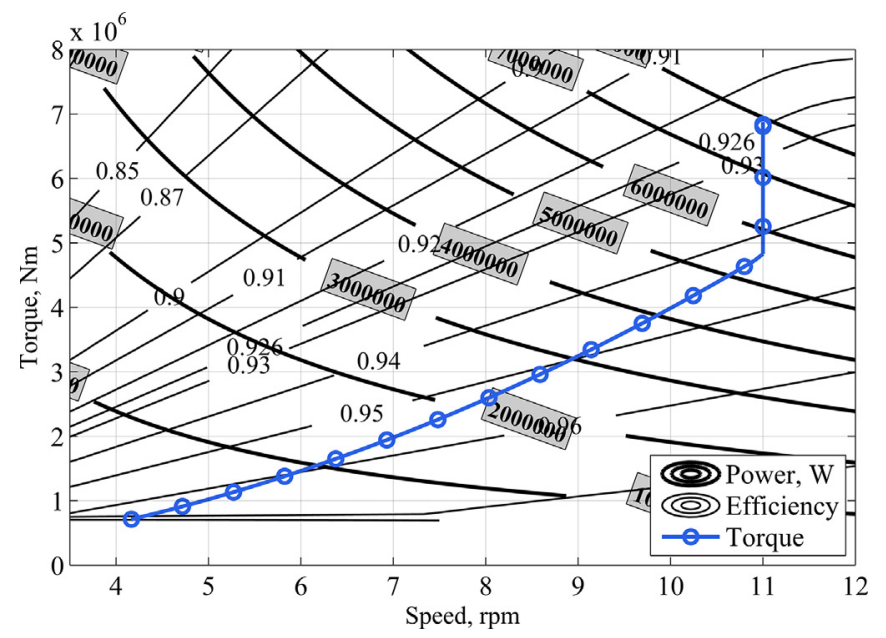

Fig. 6. $8 \mathrm{MW}$ LC DD-PMSG output torque curve drawn on the generator efficiency map.

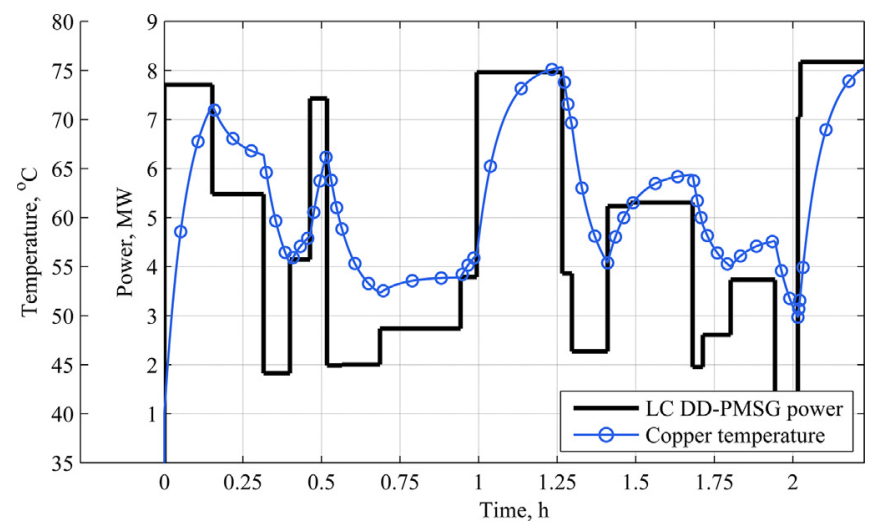

Fig. 7. Duty cycle of a variable speed wind-turbine equipped with LC DD-PMSG and LC stator winding temperature response.
Each tooth-coil in the prototype is formed from a $5.2 \mathrm{~m}$ long continuous copper conductor with a cross-sectional height of $13 \mathrm{~mm}$ and width of $15.6 \mathrm{~mm}$. There are 4 turns per tooth-coil forming two rows and four columns structure. Coolant conduits (316 series stainless steel) are embedded in the conductor copper. The conduits have an inner diameter of $4 \mathrm{~mm}$ and a wall thickness of $1 \mathrm{~mm}$. Each coil was first formed, and then the copper was wrapped with a layer of glass-fiber insulation tape (Remikaflex 45.021). A second insulating wrap covered the active lengths, bundling four straight lengths of copper conductors on each side and electrically insulating the coil from the steel laminations. The steel laminations were laser cut from SURA ${ }^{\circledR}$ M400-50A coated electrical steel. The lamination stack was bound tightly with 8 hollow 316 series stainless steel tensioning rods. Plastic caps (PEI) secured the coils within the lamination slots.

The two tooth-coils were hydraulically connected to the cooling loop in parallel by bolting them to the PEI electrically isolating inlet and outlet coolant manifold. All stainless steel tubing connections were via orbital welds or compression fittings. The steel-to-plastic interfaces were sealed with Buna-N double-seal o-rings (quad seals). Two concentric seals at each hydraulic connection offered 4 sealing surfaces to guarantee leak-free operation.

Electrically, the tooth-coils were connected in series. Incoming power was connected to the outer terminal lug of the first coil, and outgoing power was connected to the outer terminal lug of the second coil. The series connection was made using a copper bridge between the coils fastened to the inner terminal lugs.

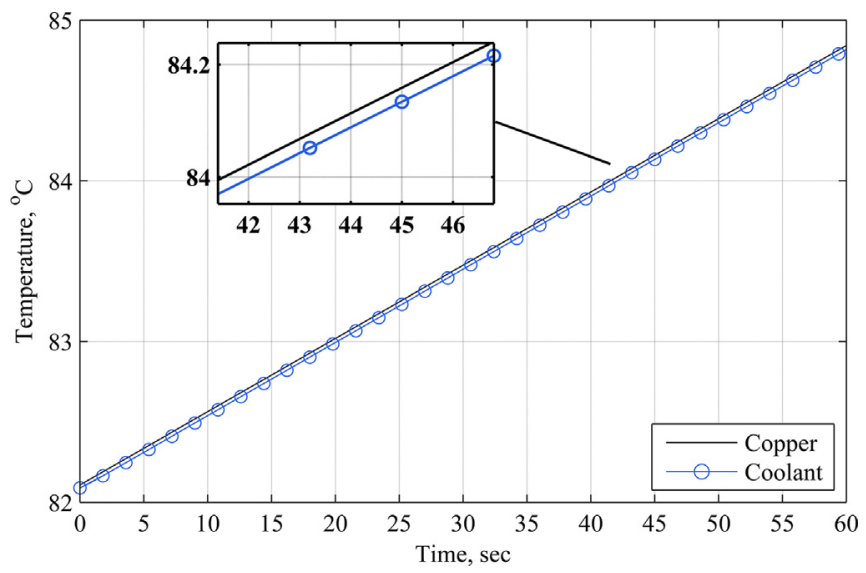

Fig. 8. Temperature rate of the copper and coolant when coolant is not circulated. 


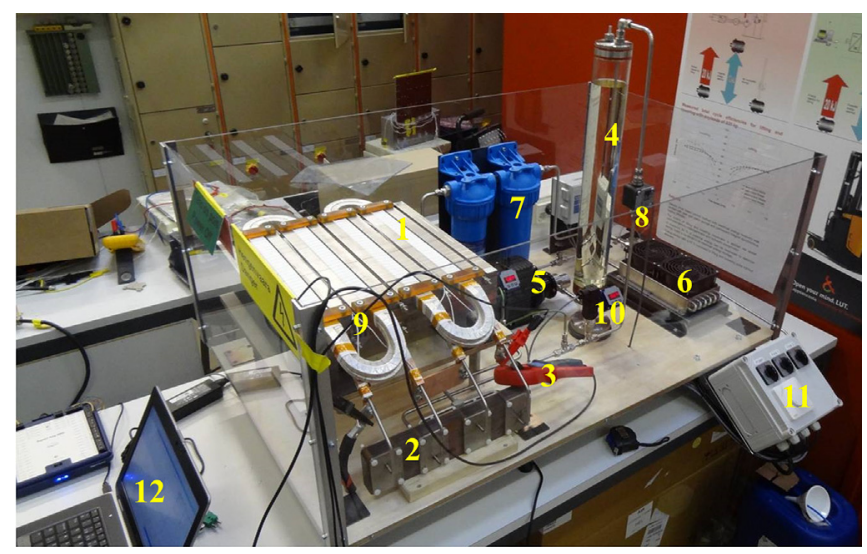

Fig. 9. Experimental setup: (1) liquid cooled tooth-coil; (2) inlet and outlet coolant manifold; (3) wires from the power source; (4) storage tank; (5) pump; (6) heat exchanger; (7) filter; (8) flow indicator, (9) thermocouple; (10) pressure indicator; (11) control system; (12) data processing system.

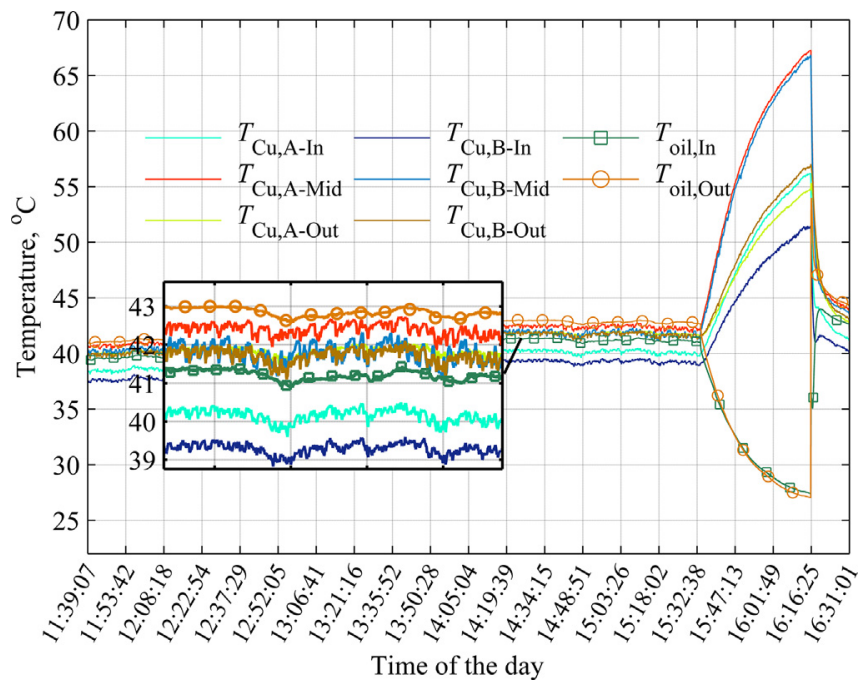

Fig. 10. Measurement results for a $5 \mathrm{~h}$ period.

To realistically evaluate the performance of a low-speed DD generator, a $1110 \mathrm{~A}, 11 \mathrm{~Hz}$ power supply should have been used to produce characteristic system losses. Such a system was not available, and a higher frequency system was used to produce losses in the tooth-coil conductors with lower current. The power source was a variable frequency $550 \mathrm{~Hz}$ synchronous generator capable of generating currents up to $150 \mathrm{~A}$, and operating continuously at 104 A (limiting by fuses overheating). To maximize joule heating, testing was carried out using the highest current and frequency that could be sustained for long periods: $104 \mathrm{~A}$ and $540 \mathrm{~Hz}$. The losses achieved using this arrangement were not sufficiently high. To further increase losses and elevate system temperatures, a $5 \mathrm{~mm}$ thick steel plate was set on top of the laminations above the coils to act as a source of eddy current loss heating. While no longer a precise emulation, the test setup can still be regarded as indicative. It made it possible to observe how effectively the cooling system could remove heat.

With power on and the plate in position, $75 \mathrm{~W}$ of heat was produced in each coil and $3.1 \mathrm{~kW}$ of heat was produced in the solid plate. Three RTDs (Resistance Temperature Devices) were installed on each coil to monitor copper temperature at the inlet, outlet, and middle of the conductor length. Inlet and outlet coolant temperature was monitored using Type $\mathrm{K}$ thermocouples. Fig. 10 shows the temperatures measured over a $5 \mathrm{~h}$ period.

On the left in Fig. 10, where the temperature curves are relatively flat, the coolant loop is operating normally with $2.05 \mathrm{l} / \mathrm{min}$ coolant flow through each coil. Coolant pressure at each inlet is $2.5 \mathrm{~Pa}$. At the approximate time of 15:40, the pump was switched off causing the coolant flow to stop. The result is the rapid increase in copper temperatures and drop in coolant temperatures shown near the right side of the plot. At 16:16, the pump was switched back on and measured temperatures quickly stabilized once again. For the duration of testing, all thermocouples were continuously monitored and recorded at $1 \mathrm{~s}$ intervals.

A 2D finite element model was prepared as shown by Fig. 11, taking into account the geometry of each part of the prototype.

Table 5 gives a summary of the steady-state results recorded during the experiment and calculated from the analytical and finite-element models.

Predicted and measured temperatures reveal similar trends and show no significant differences, supporting the suitability of the developed models. The difference between measured and calculated results is below $5 \%$ and within the measurement error of $\pm 1{ }^{\circ} \mathrm{C}$. These are accurate results, considering the thermal model does not deal with the axial direction. Results reveal that because power losses in the copper conductors are uneven, copper temperature at the middle of each tooth-coil length could be similar or even higher than copper temperature at its end, the coolant outlet. Actual copper temperatures at the coil inlets and outlets were lower than calculated temperatures. This may be due to the additional convective cooling provided by the terminal lugs and the copper bridge. Despite the low copper tooth-coil heating observed during the laboratory test, the performed thermal test demonstrates the effectiveness of direct liquid cooling. When the pump was switched off, in the second test, coolant circulation ceased, and
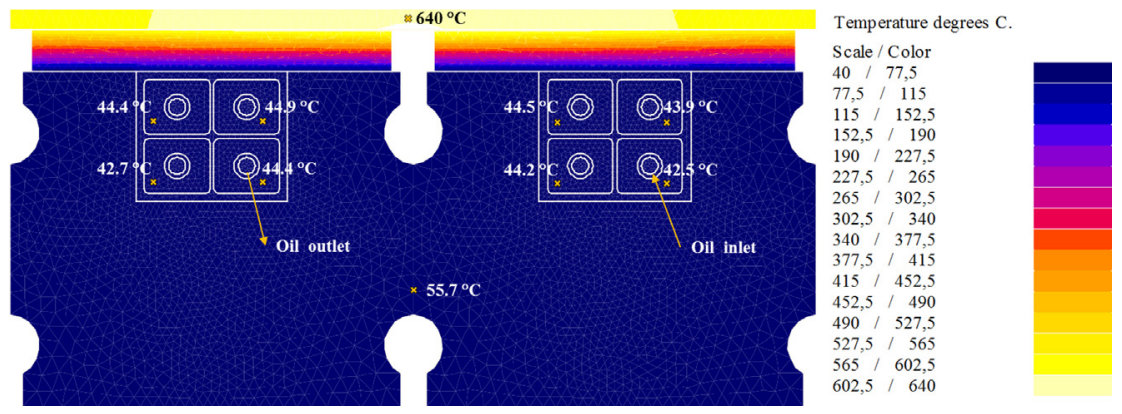

Fig. 11. Steady-state temperature predicted from 2D FEA model. 
Table 5

Comparison between measured and calculated temperatures.

\begin{tabular}{|c|c|c|c|c|c|}
\hline \multirow{2}{*}{$\begin{array}{l}\text { Measurement location } \\
\text { Inlet oil temperature, }{ }^{\circ} \mathrm{C}\end{array}$} & \multicolumn{2}{|c|}{$\begin{array}{l}\text { Averaged measured temperature } \\
\text { (between } 14: 10 \text { and } 14: 30),{ }^{\circ} \mathrm{C}\end{array}$} & \multirow{2}{*}{$\frac{\mathrm{FEA},{ }^{\circ} \mathrm{C}}{40.1}$} & \multirow{2}{*}{$\frac{\text { Analyt., }{ }^{\circ} \mathrm{C}}{40}$} & \multirow{2}{*}{$\begin{array}{l}\text { Analytical ( } 3 \mathrm{~kW} \text { per tooth-coil, } \\
\text { without solid plate), }{ }^{\circ} \mathrm{C} \\
40\end{array}$} \\
\hline & 41.3 & & & & \\
\hline Outlet oil temperature, ${ }^{\circ} \mathrm{C}$ & 43.0 & & 42.9 & 43.0 & 83.2 \\
\hline Solid plate, ${ }^{\circ} \mathrm{C}$ & - & & 640 & 603.6 & - \\
\hline Steel lamination, ${ }^{\circ} \mathrm{C}$ & - & & 55.7 & 55 & 72.9 \\
\hline \multirow[t]{2}{*}{ Copper temperature (near oil inlet), ${ }^{\circ} \mathrm{C}$} & Coil A & Coil B & 42.5 & 41.2 & 46.8 \\
\hline & 40.3 & 39.3 & & & \\
\hline Copper temperature (middle of tooth-coil length), ${ }^{\circ} \mathrm{C}$ & 42.5 & 41.9 & 44.9 & 43.7 & 85.2 \\
\hline Copper temperature (near oil outlet), ${ }^{\circ} \mathrm{C}$ & 41.9 & 41.8 & 44.4 & 43.7 & 86.4 \\
\hline
\end{tabular}

copper temperatures began increasing rapidly at $0.015^{\circ} \mathrm{C}$ per $\mathrm{s}$. The predicted temperature rate, based on Equation (8), was $0.02{ }^{\circ} \mathrm{C}$, which is good agreement between calculated and measured values. To emphasize the direct liquid cooling capability of the tooth-coil design, the last column in Table 5 gives calculated temperatures for $3 \mathrm{~kW}$ power losses in a similar tooth-coil. The temperature difference between the inlet and outlet steady-state temperatures is $43.2^{\circ} \mathrm{C}$, and based on Equation (1), the heat transferred by the oil is $2.9 \mathrm{~kW}$, showing that direct liquid tooth-coil cooling is extremely effective and a relatively simple cooling approach.

\section{Conclusion}

Thermal modeling of the 8 MW LC DD-PMSG was performed on the basis of an analytical thermal model, which makes it possible to account for uneven heat loss distribution in the stator conductors and conductor cooling arrangement. A steady-state thermal analysis with the rated thermal loading predicted a maximum temperature in the liquid-cooled tooth-coil winding under forced water cooling of $81{ }^{\circ} \mathrm{C}$ for a cooling water flow of $1 \mathrm{~m} / \mathrm{s}$. The thermal results for both the analytical thermal model and the finite element analysis were similar. To analyze generator thermal behavior under variable loading, an analytical transient thermal model was driven by a pulsed load. The thermal load was a square wave that varied with time. Results showed that LC DDPMSG power capacity may be increased without changing the cooling system.

A comparison between analytical results and finite-element calculation pointed out the suitability of the developed analytical models. Therefore, the proposed analytical thermal models can be incorporated into the electromagnetic LC DD-PMSG model to perform a multiphysics analysis.

An instrumented small prototype with two liquid-cooled toothcoils was built to provide measurement data to validate predictions. The prototype coils were tested with $104 \mathrm{~A}$ of alternating current, which produced $75 \mathrm{~W}$ of copper loss heat in each coil. No anomalous heating was observed. The prototype demonstrated the ability of effective direct cooling of the tooth-coils. When coolant circulation ceased, copper temperature began increasing rapidly.

The prototype showed the technical feasibility of the LC toothcoil design. Furthermore, this combined theoretical and experimental study strengthens the presumption that the proposed cooling approach makes an LC DD-PMSG possible and can solve the problems associated with large dimensions of future high-power DD wind turbine generators.

\section{Acknowledgements}

The authors would like to thank the Academy of Finland for their support for this research.

\section{References}

[1] Press Release Form Sway Turbine AS, Sway Turbine Unveils Details About Their 10 MW Offshore Wind Turbine, October 22, 2012. http://www. swayturbine.com.

[2] Eleven Spanish Companies Join Forces on the Azimut Project to Develop a 15MW Offshore Wind Turbine Using 100\% Spanish Technology, November 23 , 2010. http://www.gamesacorp.com.

[3] R.S. Semken, M. Polikarpova, P. Röyttä, J. Alexandrova, J. Pyrhönen, J. Nerg, A. Mikkola, J. Backman, Direct-drive permanent magnet generators for highpower wind turbines: benefits and limiting factors, IET Renewable Power Gener. 6 (1) (2012) 1-8, http://dx.doi.org/10.1049/iet-rpg.2010.0191.

[4] D. Bang, H. Polinder, G. Shrestha, J.A. Ferreira, Promising direct-drive generator system for large wind turbines, in: EPE-WECS, 2008, pp. 1-10. http://dx doi.org/10.1109/EPEWECS.2008.4497321.

[5] K. Farsane, P. Desevaux, P.K. Panday, Experimental study of the cooling of a closed type electric motor, Appl. Therm. Eng. 20 (14) (2000) 1321-1334 http://dx.doi.org/10.1016/S1359-4311(99) 00094-0.

[6] M. Fenot, E. Dorignac, A. Giret, G. Lalizel, Convective heat transfer in the entry region of an annular channel with slotted rotating inner cylinder, Appl. Therm. Eng. 54 (1) (2013) 345-358, http://dx.doi.org/10.1016/j.applthermaleng.2012.10.039.

[7] K.N. Srinivas, R. Arumugam, Analysis and characterization of switched reluctance motors: part II. Flow, thermal, and vibration analyses, IEEE Trans. Magn. 41 (4) (2005) 1321-1332, http://dx.doi.org/10.1109/TMAG.2004.843349.

[8] C. Jungreuthmayer, T. Bäuml, O. Winter, M. Ganchev, H. Kapeller, A. Haumer C. Kral, A detailed heat and fluid flow analysis of an internal permanent magnet synchronous machine by means of computational fluid dynamics, IEEE Trans. Ind. Electron. 59 (12) (2012) 4568-4578, http://dx.doi.org 10.1109/TIE.2011.2176696.

[9] D.H. Lim, S.C. Kim, Thermal performance of oil spray cooling system for inwheel motor in electric vehicles, Appl. Therm. Eng. 63 (2) (2014) 577-587 http://dx.doi.org/10.1016/j.applthermaleng.2013.11.057.

[10] Z. Kolondzovski, A. Belahcen, A. Arkkio, Multiphysics thermal design of a highspeed permanent-magnet machine, Appl. Therm. Eng. 29 (13) (2009) 26932700, http://dx.doi.org/10.1016/j.applthermaleng.2009.01.001.

11] A.M. EL-Refaie, N.C. Harris, T.M. Jahns, K.M. Rahman, Thermal analysis of multibarrier interior PM synchronous machine using lumped parameter model, IEEE Trans. Energy Convers. 19 (2) (2004), http://dx.doi.org/10.1109/ TEC.2004.827011.

[12] J. Nerg, M. Rilla, J. Pyrhönen, Thermal analysis of radial-flux electrical machines with a high power density, IEEE Trans. Ind. Electron. 55 (10) (2008) 3543-3554, http://dx.doi.org/10.1109/TIE.2008.927403.

13] N. Rostami, M.R. Feyzi, J. Pyrhonen, A. Parviainen, M. Niemela, Lumpedparameter thermal model for axial flux permanent magnet machines, IEEE Trans. Magn. 49 (3) (2013) 1178-1184, http://dx.doi.org/10.1109/ TMAG.2012.2210051.

[14] K. Li, S. Wang, J.P. Sullivan, A novel thermal network for the maximum temperature-rise of hollow cylinder, Appl. Therm. Eng. 52 (1) (2013) 198208, http://dx.doi.org/10.1016/S1359-4311(99)00094-0.

15] J. Zhang, X. Li, M. Vance, Experiments and modeling of heat transfer in oil transformer winding with zigzag cooling ducts, Appl. Therm. Eng. 28 (1) (2008) 36-48, http://dx.doi.org/10.1016/j.applthermaleng.2007.02.012.

[16] M. Polikarpova, P. Röyttä, J. Alexandrova, S. Semken, J. Nerg, J. Pyrhönen, Thermal design and analysis of a direct-liquid cooled direct drive permanent magnet synchronous generator for high power wind turbine application, in: XXth International Conference on Electrical Machines (ICEM), 2012, pp. 1488-1495. http://dx.doi.org/10.1109/ICElMach.2012.6350075.

[17] Y. Alexandrova, S. Semken, M. Polikarpova, J. Pyrhönen, Defining proper initial geometry of an $8 \mathrm{MW}$ liquid-cooled direct drive permanent magnet synchronous generator for wind turbine application based on minimizing mass, in: XXth International Conference on Electrical Machines (ICEM), 2012, pp. 1250-1255. http://dx.doi.org/10.1109/ICEIMach.2012.6350036.

[18] H. Jussila, Concentrated Winding Multiphase Permanent Magnet Machine Design and Electromagnetic Properties - Case Axial Flux Machine (PhD thesis), Lappeenranta University of Technology, Lappeenranta, Finland, 2009.

[19] D. Staton, A. Boglietti, A. Cavagnino, Solving the more difficult aspects of electric motor thermal analysis in small and medium size industrial induction 
motors, IEEE Trans. Energy Convers. 20 (3) (2005) 620-628, http://dx.doi.org/ 10.1109/TEC.2005.847979.

[20] E.Ya. Kazovskij, Y.B. Danilevich, E.G. Kasharskiy, G.V. Rubisov, Abnorma Operating Conditions of Large Synchronous Machines, Nauka, Leningrad, USSR, 1969.

[21] Permissible Loading of Generators and Large Motors, Facilities Instructions Standards, and Techniques, vol. 1-4, 2000.
[22] International Standard IEC 60034-1:2004(E), Rotating Electrical Machines Part 1: Rating and Performance, eleventh ed., 2004-04.

[23] J.P. Holman, Heat Transfer, McGraw-Hill, Singapore, 1989.

[24] G.G. Chastlivij, G.M. Fedorenko, V.A. Tereshonkov, V.I. Vigovskiy, Electrical Machines with Liquid Cooling, Naukova Dumka, Kiev, USSR, 1989.

[25] E.I. Gurevich, Yu.L. Rybin, Transient Thermal Processes in Electrical Machines, Energoatomizdat, Leningrad, USSR, 1983. 